INTERNATIONAL DESIGN CONFERENCE - DESIGN 2018

https://doi.org/10.21278/idc.2018.0505

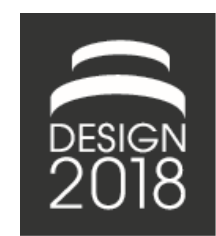

\title{
TRACEABILITY OF DECISIONS IN PRODUCT REALIZATION PROCESSES OF CUSTOM ENGINEERED PRODUCTS
}

\author{
F. P. W. Elgh, J. Johansson, M. Pookrkiany, R. Stolt and D. Raudberget
}

\begin{abstract}
Custom engineered products require an engineer-to-order approach in development, quotation preparation and order processing. This work reports the result of a three-and-a-half-year project were the objective was to develop means for implementation and management of computer support for engineering design and production engineering of customized products. Efficient re-use is essential for success and decision is identified as the core concept to trace tasks executed, knowledge used, design rationale and artefacts developed throughout the product realization process.
\end{abstract}

Keywords: design knowledge, information management, process modelling, customisation, engineer-to-order

\section{Introduction}

Mass customization (Hvam et al., 2008), with the possibility to design and manufacture highly customer adapted products, brings a competitive edge to manufacturing companies. Individualized products, resource-smart design and production, and a focus on customer value have been pointed out as three opportunities for Swedish industry to stay competitive on a globalized market (Vinnova, 2011). However, this requires further development and integration of the knowledge-based enabling technologies in industry (AIAG FoF PPP, 2010). Highly custom engineered products require the adoption of an engineer-to-order approach in development, quotation preparation and order processing. This allows products to be adapted to large variations in the customers' specification which brings more value to the customer and profit to the company by efficient utilization of material and manufacturing resources. To quickly go from answering a request for quotation, engineer the product and move it into production, while maintaining the most competitive pricing, is based on the exercising of a very rich and diverse knowledge base about the products, their production and the required resources for design and manufacture. To successfully achieve this requires utilization of systems for efficient design of product variants with associated specifications for automated manufacturing.

The development and implementation of systems for automated design and production preparation of customized products is a significant investment in time and money. The complexity and scope of these systems can vary from applications to be used as a support in the design process, to fully automated systems for the design and production preparation. Regardless of the complexity and scope, experience has shown that problems often arise when a system is to be implemented in current operations as well as in its long-term management.

This was the scope of a project that started 2014-04-01 and ended 2017-09-30. The project was executed in close collaboration with four industrial partners and a research team from academia. The total 
turnover of the project was $1,150 \mathrm{~m} €$ of which over $50 \%$ was financed by the industry partners. The project objective was to develop models, methods, and tools to support efficient implementation and management of computer support for efficient design and production engineering of highly customized products.

\subsection{Research method and approach supporting collaboration}

A significant part of the project was focused on the development of general methods and models which were devised, evaluated, refined and validated by industrial case studies in executed in collaboration between industry and academia. The starting-point in industrial problems is in accordance with problem-based research and the project followed the well-established design research methodology (DRM) described by Blessing and Chakrabati (2009), see Figure 1. The system development method (Burstein, 2002) was deployed for the purpose to explore the research issues which includes the introduction, evaluation, and refinement of new concepts. In this work, these concepts are prescriptive methods and models that systematically evolve according to the design modelling research approach that focus on the development of computer support (Duffy and Andreasen, 1995). The project applied a spiral model, where theoretical and practical insights drive the methods' and models' development. The initial methods and models were hypothesis put to test by the industrial cases. The applicability was evaluated, and the result used to guide the improvement of the methods and models.

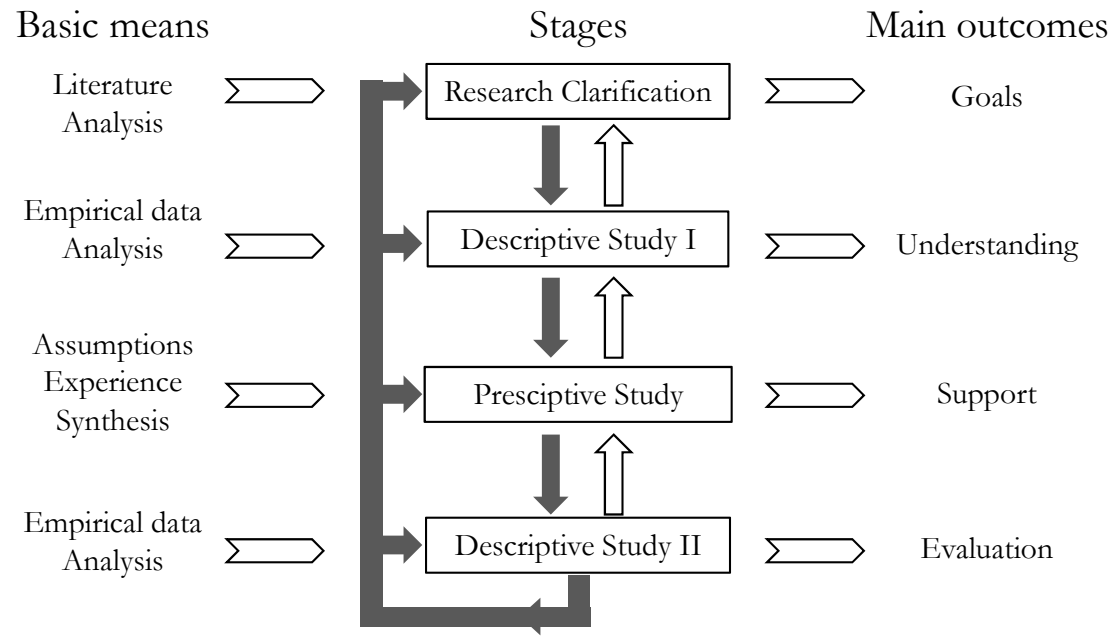

Figure 1. The design research methodology - DRM (Blessing and Chakrabati, 2009)

The project research scheme was based on an extension of DRM with four cases (C1-C4), see Figure 2. The project started with a descriptive study to outline initial activities, practices and methods at the companies followed by a preliminary definition of the criteria governing the research. The knowledge and understanding were further expanded with an extended review of existing methods and models published in scientific literature. The work on the industrial cases was then initiated, where selections of products/applications were studied and analysed in detailed. The detailed knowledge of the industrial practice was required to ensure a complete understanding of the industrial activity and that no critical aspects were overlooked. The comprehensive and detailed knowledge gained through these activities supported the final selection and definition of the guiding criteria. Based on the results from the work on the industrial cases and the review of the scientific literature, prescriptive methods and models were defined taking into account the criteria to meet industrial challenges and needs. This was followed by work on the industrial cases where the methods and models were tested for a number of selected products/applications. The results were then evaluated and used as the basis for revision and adaptation of the prescriptive methods and models. A third phase of work on the industrial cases was executed for the purpose to improve the methods and models. The results from the individual cases were empirical data that provided an opportunity for cross-case analysis. 


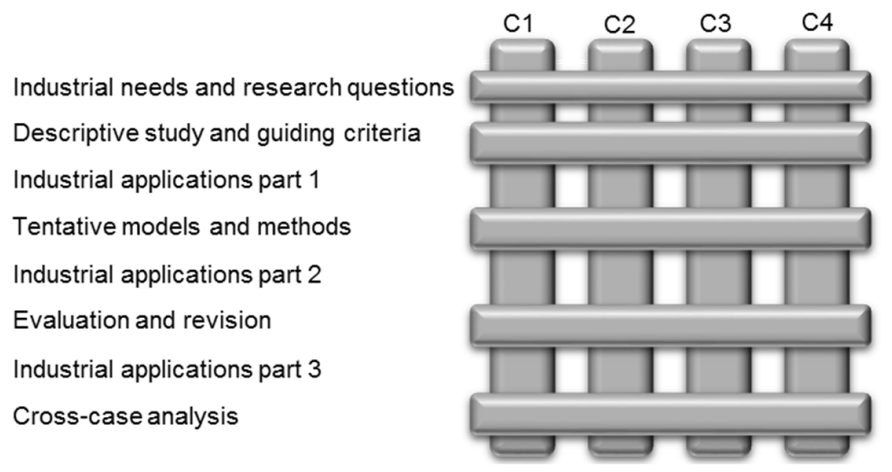

Figure 2. Project research scheme including four cases (C1-C4)

\section{Methods and models supporting system development}

There are numerous examples in Swedish industry where systems supporting custom engineered products have been applied with varying methods and degree of sophistication. The most common applications in industry are various forms of configuration systems (Claesson, 2006; Hvam et al., 2008), but there are also many applications regarding parametric component design (Cederfeldt and Sunnersjö, 2003; Amadori et al., 2012), structural analysis tasks (Isaksson, 2003; Boart, 2007) and systems of a more generative nature (Ryhänen, 2004; Elgh and Cedefeldt, 2007; Elgh, 2012). There are mainly three classes of systems, either are they based upon the configuration of a set of predefined product modules and attributes (configuration systems), or the automation of different engineering tasks generating a product definition (design automation), or the definition of rules representing engineering knowledge which operates on a parametric geometry model (knowledge-based engineering, KBE). The two latter can work as mean in an engineerto-order process and the former in a configure-to-order process. It is foremost the work in the area of design automation and knowledge-based engineering that are relevant in this work, however, the progress in configuration systems is interesting as it might provide methods that partly can be applicable and useful. A method for how to plan a new design automation system is described by Sunnersjö (2012). A top down approach, starting from specification of system requirement and the problem characteristics is described followed by a mapping to appropriate methods for system realisation. The contribution does not include aspects such as user-friendliness, maintainability or documentation despite the author's statement that they are of significant importance to success in industrial praxis. Implementation and management issues are argued to be considered only when the fundamentals of the problem have been solved. A set of criteria of system characteristics is defined by Cederfeldt (2007), including transparency, knowledge accessibility, flexibility, ease of use and longevity. Most likely, these characteristics affect system implementation and management. The criteria are to be considered and weighted in the planning of a design automation system, however, the author state that they do not give concrete answers on implementation and management issues. A procedure for development of design automation systems has been outlined by Rask (1998), where issues about documentation and maintenance are addressed by emphasizing the need and importance of routines regarding versioning, verification and traceability. A possible means to support the updating of the knowledge-base is to strive for a design automation system implementation that allows the revision and the documentation to be executed at system runtime (Rask et al., 2000). Stokes (2001) described a methodology for the development of knowledge-based engineering applications called MOKA, Methodology and software tools Oriented to Knowledge Based Engineering Applications. Two central parts of the methodology are the Informal and Formal models. The Informal model is used to document and structure knowledge elicited from experts, handbooks, protocols, literature etc. The Informal model can be regarded as paper-based with text and illustrations. The Formal model is derived from the Informal model with the purpose to model and structure the knowledge in a fashion suitable for system specification and programming. The Formal model is described by an object-oriented annotation called MML that is based on UML. The Design and Engineering Engine, DEE, is another approach for the development of knowledge-based engineering applications (La Rocca et al., 2002; Lisandrin and van Tooren, 2002; van Tooren et al., 2003). This approach consists of three major elements: The first element is concerned with the design process, which includes multidisciplinary optimisation. The second major 
element is the Multi-Model Generator (MMG) that uses the product model parameter values in combination with formalised domain knowledge to generate product models. Report Files are generated and fed to the third major element, the detailed analysis modules. These modules calculate the design implications. Finally, the loop is closed by analysing the data files using convergence and evaluation checks. Curran et al. (2010) extends the DEE approach to the Knowledge Nurture for Optimal Multidisciplinary Analysis and Design, KNOMAD, methodology. The KNOMAD acronym highlights method process of: $(\mathrm{K})$ nowledge capture; (N)ormalisation; (O)rganisation; (M)odeling; (A)nalysis; and (D)elivery. These implementation steps are taken and repeated as part of the knowledge life cycle and in this context, KNOMAD nurtures the whole Knowledge Management across that life cycle. Further, this method includes an approach for multidisciplinary design (optimization) and for knowledge capture, formalization, delivery and life cycle nurture. Despite the methods described above and the numerous KBE applications developed and describe in scientific publications, a number of issues to be research still exists. This is supported by an extensive review by Verhagen et al. (2012) where the major shortcomings of KBE have been identified. Four of these that most likely have impact on implementation and management are: system transparency, knowledge sourcing and re-use, semantics of knowledge models and traceability.

Hvam et al. (2008) describe a complete and detailed methodology for constructing configuration systems in industrial and service companies. They suggest an iterative process including the activities: analysis of product portfolio, object-oriented modelling, object-oriented design and programming, among others. Every activity results in a description of the problem domain with different levels of abstraction and formalisation. The analysis of product portfolio results in a Product Variant Master (PVM) and Class Relationship Collaboration (CRC) cards. The maintenance is proposed to be organised by introducing Model managers. The Model managers are responsible for the delegation, coordination, collection and documentation of domain expert knowledge. This documentation is then used by the programmers to update the system. Haug et al. (2007) have developed a prototype system for the documentation of configuration systems that is founded on one data model. This documentation system is separated from the implemented product configuration system. Documentation is in both cases above considered as an important enabler for efficient maintenance. Claesson (2006) have introduced and developed the concept of configurable components. The concept includes a function-means model to provide design rational for the encapsulated design solutions which could support the understanding of the system and thereby support system implementation and maintenance - this is, however, not surveyed.

\subsection{Knowledge gap}

As can be concluded from the above, extensive research and development have been devoted to technical aspects of building systems for specific products, and some research have been directed towards general methods and models supporting system development, although, little attention has been paid on the actual implementation and management of systems in operations. Our experience from industry indicates that significant efforts are required to introduce and align these kinds of systems with existing operation, legacy systems and overall state of practice. System management including adapting existing systems to changes in product technology, new product knowledge, production practices, new customers and so forth is also challenging. Research in design automation and knowledge-based engineering has not focused on implementation and management issues in industrial operation. The aspects are pointed out as important but merely treated as consequences of other actions without studying the actual need, trade-offs in development and supporting methods and tools required. Concerning configuration system, documentation has been pointed out as important for maintenance issues and different models and tools exist to be used as support. The main principles are interesting and are most likely applicable to some degree, however, there is no evidence that the specific methods and tools can support an engineer-to-order business model. In previous research (Elgh and Poorkiany, 2012; Elgh, 2014), the traceability of design rationale was identified and explored as an enabler for improved system implementation and system management. Engineering design is a process of many successive decisions in a large solution space (Andreasen and Hein, 1987) and it is required to actively capture design rationale throughout the complete set of design decisions to ensure it completeness. The scope of this work is to further explore this with a focus on traceability of decision and support for industrial practice. 


\section{Results}

The work was conducted according to the method described in section 1.1 and the results are in this chapter presented as a unity. First, the scope, need and focus for each case is described. This is followed by a comparison, the identification of shared need and focus, and the outline of a target condition. The final solutions for the cases are summarized and subject for a cross-case analysis.

\subsection{Scope, need and focus}

Case Company 1 is a worldwide supplier of insert stapling units for copiers, printers and document handling systems. The company had recently been incorporated under a larger brand given the directives to focus and strengthen their position as a worldwide supplier of insert stapling units for copiers, printers and document handling systems. The insert stapling units is developed and manufactured on contract with different OEMs. Every unit model has to be adapted to the system it will be an integrated part of. A product platform has been defined to cut product cost and development lead time. The platform is based on a modular product architecture to be configured for the different OEM's individual specification. However, the platform covers only a limited part of the product design and additional custom engineered parts have to be added. Activities directed towards formalization and structuring of knowledge in applications supporting the engineering of unique parts have been taken by individuals, but they are not shared on a corporate level. Support to incorporate and align these applications with the development process and provide support for documentation of information and knowledge during the course of product development, enabling capturing and structuring of design rationale, was expressed as an initial focus.

Case Company 2 is a global manufacturer of a wide assortment of products for transporting equipment by car, including roof racks, bike and water sport carriers and roof boxes. The company sees an opportunity to considerably cut time and cost in their development and manufacture of roof racks for cars by the implementation of a system for the customization of rack attachments to new car models. Every car model requires an individual adapted attachment consisting of a footpad and bracket and currently there exist more than 400 footpads and 1100 brackets. To be able to quickly launch a roof rack for a new model is considered as very important as it is common that a roof rack with accessories to be mounted on the rack is included as additional equipment when a new car is bought. The company was working on the development of a system that would enable reuse of existing attachments. Parts of the system was used in operation globally at the company and hade proven to reduce the development lead time, reduced the number of new designs and significantly reduced both the development and the tooling cost. When the system is about to be fully integrated into the development process it will become a strategic tool for business success and new needs have emerged concerning maintenance, expansion and traceability. An efficient method for documentation of information and knowledge during system development was expressed as an initial focus.

Case Company 3 is a global actor in the area of development, production, service and maintenance of components for aircraft, rocket and gas turbine engines with high technology content. The company provides products that are completely custom engineered in an internationally market with high competition. The products are integrated in complex systems working in extreme environments for long time periods with both customer and legal demands for complete documentation and traceability. The company takes full responsibility for the functionality of their products during its operation, including service, maintenance and updates. Fulfilling these harsh requirements is a challenge but at the same time an opportunity to sustain a competitive edge. Automation of design and production preparation by the use of knowledge-based engineering (KBE) has been used at the company for more than a decade to enable adaptation to changes in customer specifications and evaluation of different design solutions. Complete documentation and traceability of products, knowledge and information during decades of operation are required. To manage different versions of applications, their underlying information and knowledge, the products in operation and the relations between all these have been identified as critical challenges at the company. New methods, models and tools that support the company in building an infrastructure and an environment focusing on the challenges was expressed as an initial focus. 
Case Company 4 is the world's leading supplier of tools, tooling solutions and know-how to the metalworking industry. The company is active in an internationally very competitive market and needs to constantly cut development lead time by seeking means to improve their processes. The company has a long-standing tradition in automation of quotation and order processes and has adopted an engineer-to-order business model supported by systems for automated design and production preparation of customized product. A request for quotation of a custom engineered product is replied within 24 hours including detailed design drawings and a final price. All the necessary documents and manufacturing programs are automatically generated when the bid is accepted by the customer. Maintenance and re-use of system models and underlying knowledge have been identified as critical regarding systems' longevity and development lead time at the company. Methods and tools for design space definition and documentation together with support for traceability, versioning and domain views on system encapsulated information and knowledge was expressed as an initial focus.

\subsection{Comparison, shared need, focus and target condition}

The companies act in different areas of the market and are of varying size from a few hundred up to 8000 employees. All companies adopt an Engineer-To-Order (ETO) approach to fulfil customer unique requirements. The companies cover a range spanning from the industrial frontier in utilization of engineering support systems to companies with less experience in the field. While Company 1 might be considered as somewhat behind the average company regarding utilization of engineering support systems, Company 3 would be representing the frontier with many academic employees and $\mathrm{PhDs}$ which performs work and research in related areas, especially KBE and DA. The company is aware of existing methods but cannot find the desired support in them for their activities. Company 4 is also far ahead of the average company with an in-house developed programming language adapted for creating design automation applications and long experience within the area. Company 2 are ahead but closer to the average company in its utilization of engineering support systems. A few systems exist within the company, but they are new in the area with less experience. The information and knowledge produced during product design and development at the companies include product geometries, drawings, material specifications, bill of materials, process plans, CAD/CAM programs, inspection routines, cost estimations and assembly instructions. The information and knowledge originate from, and is associated to, a variety of sources and process stages, and have complex dependencies and relations that constraint the range of products that can be produced and the allocation of resources for engineering and manufacture. The quality of the information and knowledge are varying and the tracing, revising and maintenance is challenging. To tackle this, the shared research effort agreed upon was to devise and refine models and methods that support the capturing, structuring and access to the information and knowledge produced during product design and development of systems supporting product customization. This includes not only the information needed for system development supporting quotation, design and production preparation processes, but also the meta-information, by example the origin, the rationale, stakeholders and dependencies. A workshop with companies' representatives was conducted to outline characteristics of a target condition. The result was further discussed at the companies followed by a prioritization. The work resulted in the following criteria:

- Reduced time making documentation

- Less time spent to access and understand the documentation

- Increase resource efficiency

- Decrease mistakes

- Faster changes to products

- Increased quality of documents

- High user acceptance

- Increased confidence in system

- Reuse of Knowledge Base 
Reduced time making documentation was considered most important followed by Less time spent to access and understand the documentation. The others were graded as equally important without any clear priority. These criteria were to be considered and guide the work of developing novel support.

\subsection{Final solutions}

Case 1. The work focused on the flow of design knowledge and how this can be improved in the organisation. Over time, engineers forget rationale, they change positions or even leaves the company and a loss of knowledge is a fact. The company expressed a need of novel support to tackle this by making the knowledge capture, storage and re-use more efficient and improve the knowledge management process. A focus was set on the early phases where creativity and idea-generation are dominant. The company had an in-house developed project management system based on a stage model using cases and activities in combination with issues that are posted, resolved and approved by comments and meta-data. However, there were no support for early phases and attaching documents or other files that in more detailed described the problems, ideas, potential solutions, argumentation and decisions. A way to easily store engineering documents in the existing project management system was developed. The idea generation process was improved by introducing the formal methodology of Instant Set-based Design (Ström et al., 2016) together with tools for idea evaluation and elimination. A means to add a knowledge management process into the existing project management system that support Instant Set-based design was created, including a new class of cases called Innovation where concept information (e.g. idea sketches, tests, concept evaluation preliminary CAD models, calculations and documents) can be stored in one place (Figure 3). This will provide a standardized way of working and supports access to information on various levels of granularity by search mechanisms.
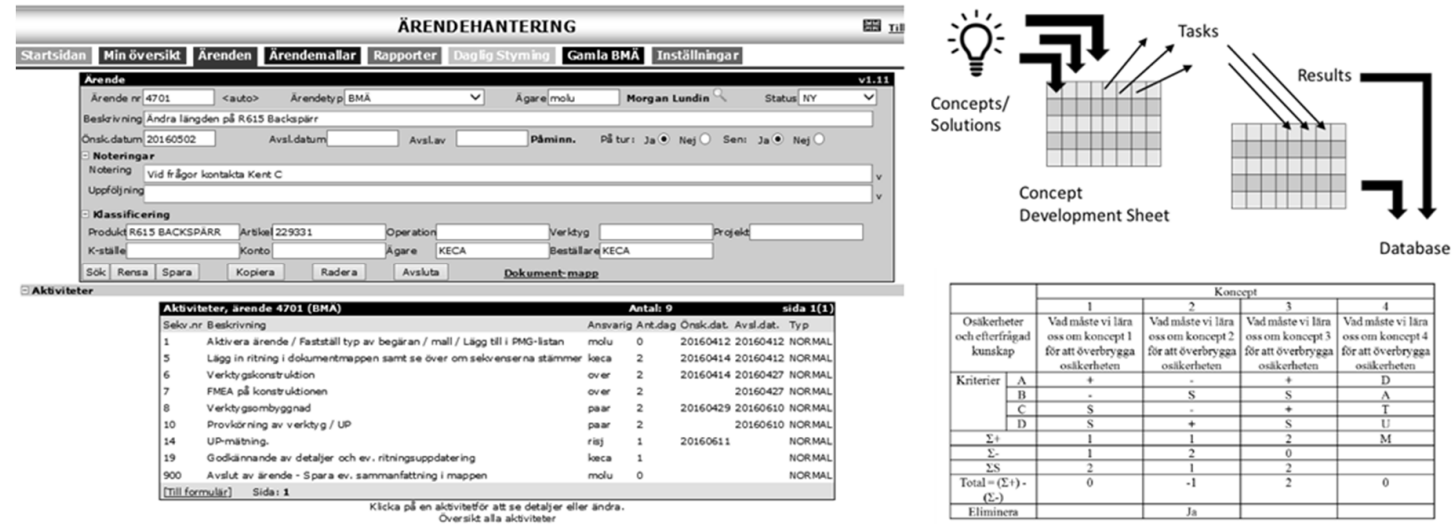

Figure 3. Updated project management system for capturing concepts, decision etc. in early phases with supporting documentation e.g. concept development and concept evaluation sheets (partly in Swedish)

Case 2. Decisions can be made throughout the entire product life-cycle and design rationale should be captured at its origin. This was supported by providing an integrated digital environment were the tools for capturing design rationale, as well as representing it, are integrated to software already used by the engineers. The engineers can perform design tasks in different software and applications, and concurrently capture design rationale. Design rationale can be represented in the formats that the engineers prefer to work with. A prototype system was developed based on an extended information model, and the integration of SolidWorks, Microsoft Word, Microsoft Excel and wiki pages. SolidWorks was chosen as representative for 3D modelling, Microsoft Excel for rules definition and drawing tables, and Microsoft Word for specifications and textual content. Beside these software, wiki pages were chosen as the fourth part of the system to enable explicit descriptions to be structured to which detailed descriptions in the other software could be mapped. The system was tested in tooling design phase. Figure 4 show how the design rationale system was integrated with SolidWorks and Microsoft Word. 


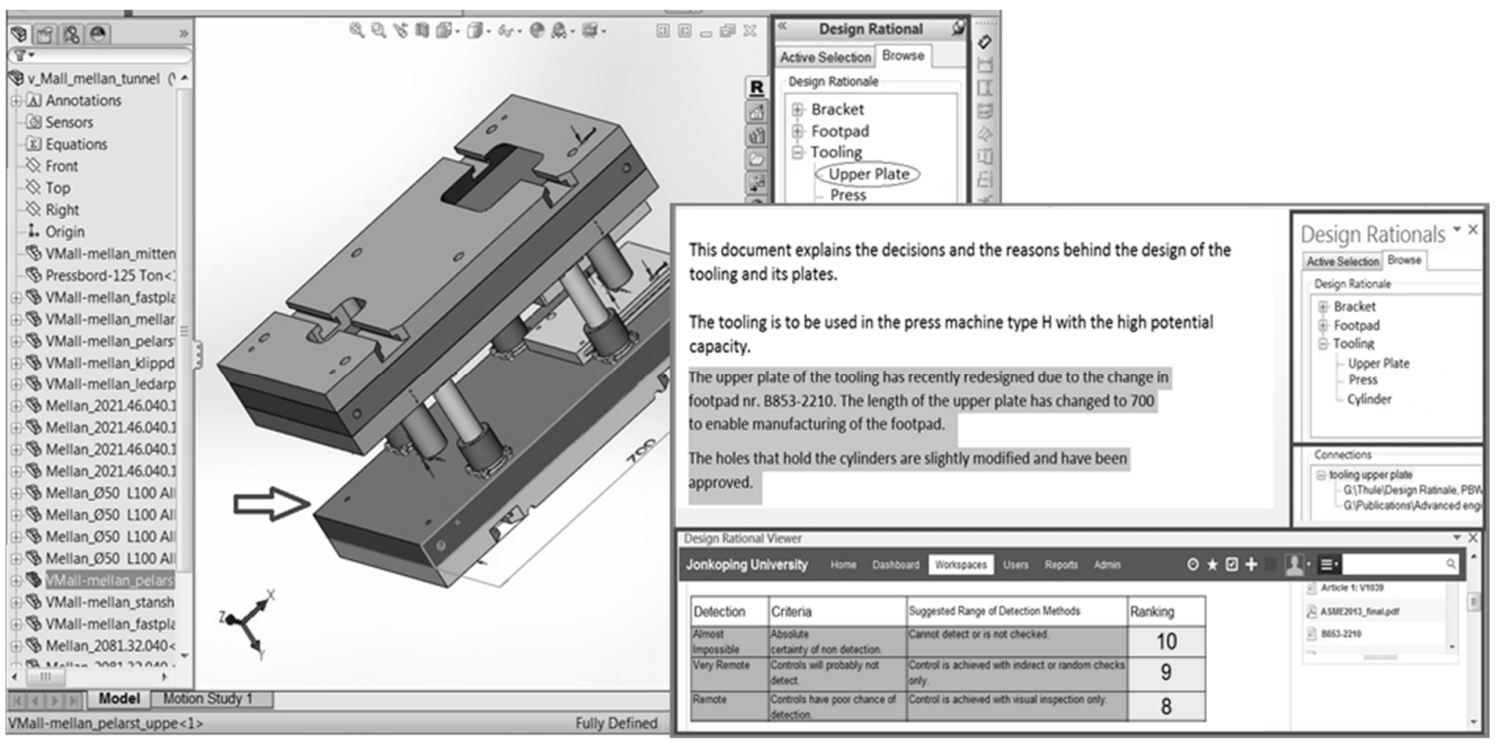

Figure 4. Integration of means for design rationale management in software applications

Case 3. The work focused on the connectivity between the functions in design automation systems. More specifically in this case, methods have been developed that can trace the dependencies between software, scripts (.KF, .py, .vb, vba), data, and information sources and to maintain these dependencies over time. Dependencies span from a single document to sections of documents. The sections of the documents are defined by "tagging" meaning highlighting a part of document by inserting comments or similar. A special software called DM (Design Manager) was developed and implemented in an automated system for multidisciplinary design evaluation used at the company. The design evaluation system consists of many different types of documents. DM allows the user to add tags in most types of documents and automatically or manually define the dependencies between them. DM can also automatically trace all tags and the dependencies allowing graphs to be generated. GraphML-files is used to store tags and relations which allows for graphs to be generated directly. It is also possible to add meta-data to the dependencies containing information such as author, type of script, creation date and modification date. This will improve the understanding of dependencies and thereby facilitate the maintenance of the multidisciplinary design evaluation. A graph of the dependencies between some of tagged documents at the company is seen in Figure 5.
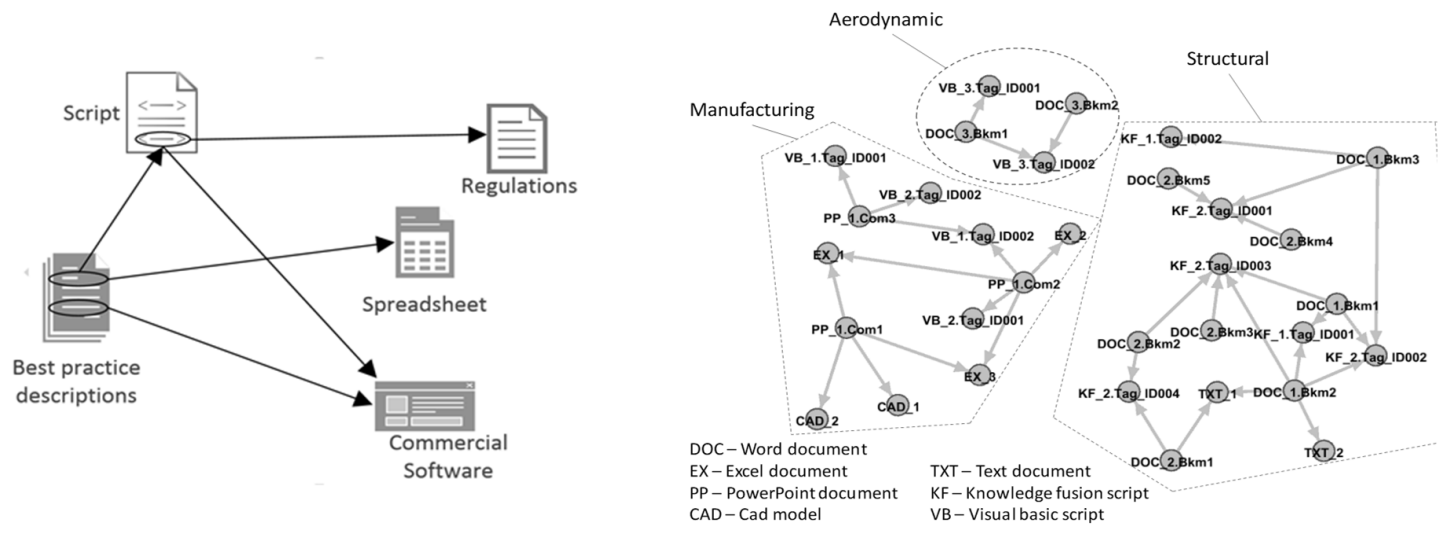

Figure 5. Principle of dependencies and a set of dependencies visualised as a graph

Case 4. The focus of the case was to trace connections between concepts, rules and geometry as defined in the domain specific programming language developed at the company for design automation. The ultimate goal was to have a complete model containing both logic and rationale. After the first evaluation 
phase, it was realized that content is missing, and the effort was put on how to capture rationale from engineers during the product and system development. Representation methods and templates (Figure 6) were developed for design rationale (QOC-sheet, MindManager) together with a prototype system that displays filtered design rationale in the CAD context to one of the down streams stakeholders (special designers). Means to interactively display connectivity graphs within the integrated development environment (IDE) were implemented, which enable an active way of sharing design rationale, and support to filter and export design rationale as EPUB-files for entire product family or for product instance based on the execution flow (EPUB/PDF).
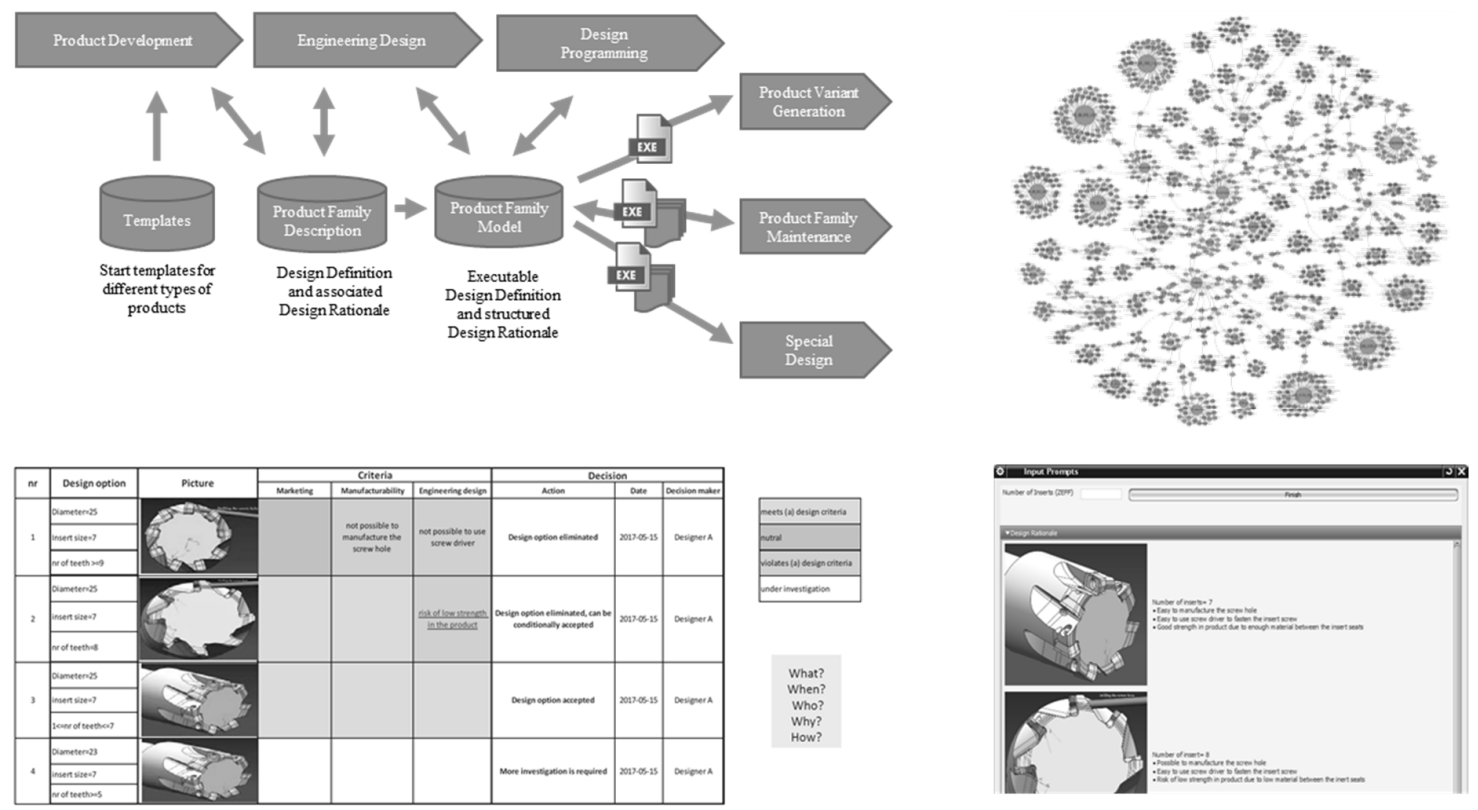

Figure 6. Development process and structuring of design rationale in early phases together with connectivity graph and in-context rationale

\subsection{Cross-case analysis}

The project has resulted in a number of methods and models with different scope:

- A method for documentation of information generated in problem-solving and creative sessions in conceptual design.

- A method to capture, structure and share design rationale supporting the collaboration between product design and tooling design in a distributed environment.

- A model that supports domain specific views on system encapsulated information and knowledge with the possibility to extract selections with various levels of granularity and from different phases in the development process.

- Principles to enable traceability across products, system models and underlying information and knowledge.

- A method for creating and maintaining relations between system revisions and design space revisions.

- A method with associated documentation that supports the process of going from a limited number of validated physical product instances to a design space drawn by rules and parametric models representing product definitions, process plans and cost estimations.

- A method for documentation of information and knowledge during the course of product and system development enabling capturing and structuring of design rationale, including both the physical artefact and the system.

At a first glance, it can seem that these methods and models are unique, however they share some parts and together they can form a unity. The companies are quite different when it comes to size, products, 
sales volumes, level of design automation etc. There is one similarity that will have an essential impact on documentation, design rationale management and traceability across different domains and that is the fact that they all work according to an engineer to order influenced business model. They have different classes of design assets that form a design platform (Elgh et al., 2016; André et al. 2017) for a product concept and these assets are used in the development of customer specific products (Figure 7).

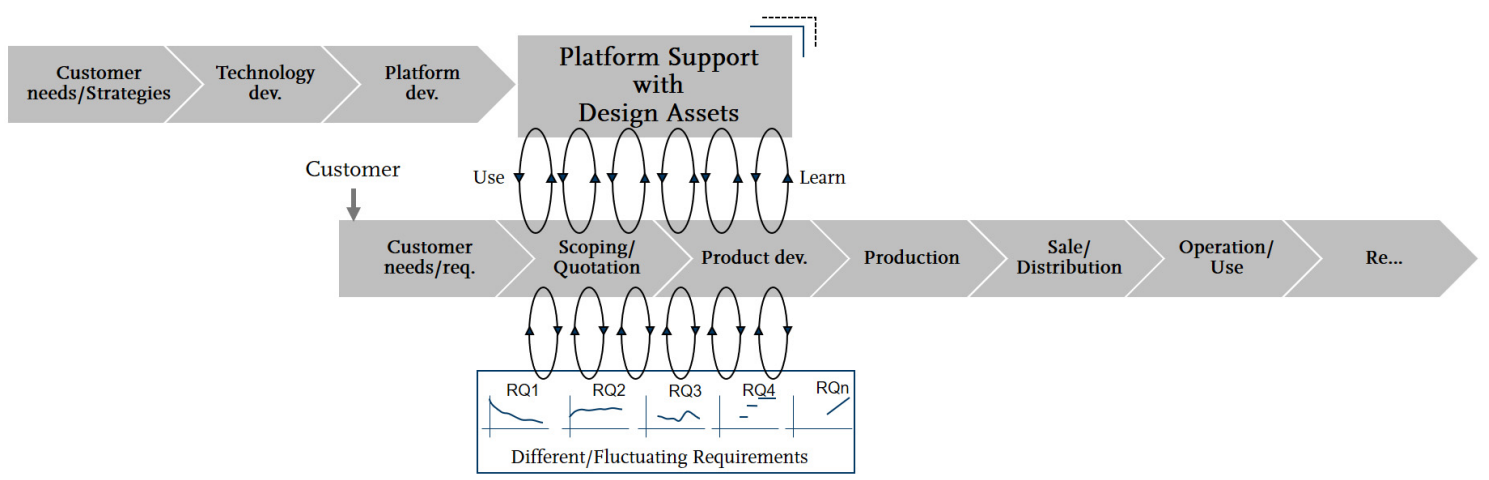

Figure 7. Product realization process for highly customized products including platform support with design assets

The most essential concept in the solutions that where developed for the four companies is Decision. If the process above is viewed as a sequence of decisions using knowledge from various sources, a product realization process can be outlined and the scope of the four cases can be depicted (Figure 8).

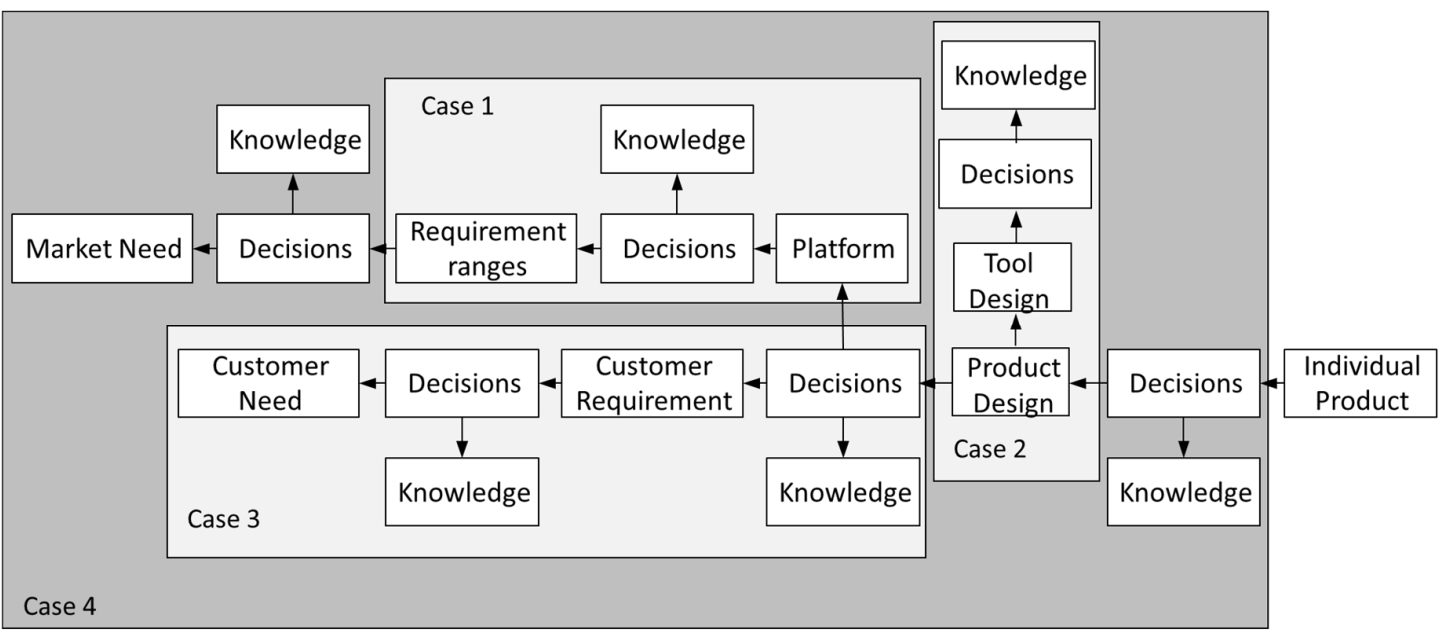

Figure 8. Product realization process including decision activities with traceability links

Two life-cycle perspectives have to be considered when addressing management - a knowledge perspective and a product perspective. Management concerning knowledge includes the adaptation of rules and models to changes in production technology, new product knowledge, new markets, changes in legal requirements, etc. Issues related to flexibility, stability, quality assurance, traceability and documentation of a system's different constituting parts and underlying knowledge can be critical unless adequate measures have been taken in the development phase. Management concerning the product focuses mainly on documentation, traceability and version control. As the governing framework and models are updated and refined due to shifting prerequisite, the system and the solutions generated for a single specification will change over time. This affects product management and the ability to meet legislation and customers' requirements regarding documentation and traceability, as well as the company's ability to provide services, maintenance and supply spare parts. Of importance are issues 
relating to methods of generating and managing documentation such as engineering calculations and simulations combined with the principles of traceability from the product to the underlying knowledge and vice versa, and versioning of rules, models and systems.

\section{Conclusions}

Highly custom engineered products require the adoption of an engineer-to-order approach in development, quotation preparation and order processing. Efficient re-use is critical, and decision is identified as the core concept to trace tasks executed, utilised knowledge, design rationale and artefacts developed throughout the product realization process. Decision is the core concept for knowledge capture, rationale and documentation, however, support for traceability across domains is required to ensure fine granularity. To succeed in industrial practise entails proactive measures to be taken together with the existents of expedient support, which includes:

- A careful identification and limitation of future stakeholders and their need

- Means to manage alternative solutions

- Alternative structuring principles as a product structure does not exist in early phases

- Incorporation of argumentation

- Classification of the origin of argumentation

- Mapping of the origin of argumentation to support traceability

- Support mapping with fine granularity

- Integrated means for documentation in existing engineering software

- Integration of the rationale model and the automation model in later phases to avoid duplication

- Versioning control of the rationale model and the automation model

- Means to extract and provide information for different stakeholders

The four cases demonstrate how to use the decision concept to support documentation, enable traceability across activities and give access to supporting argumentation. The four cases cover the whole domain although focusing on different aspects. At this stage, the focus has been on the more technical side of the problem were issues concerning organisational structures, company processes, legacy systems, upscaling, and maintenance have been considered but not completely investigated, and this has to be done in future work.

\section{Acknowledgment}

The authors would like to express their gratitude to the participating companies in the project as well as The Knowledge Foundation for financial support.

\section{References}

AIAG FoF PPP (2010), Factories of the Future Road Map PPP Strategic Multi-annual Roadmap, The European Factories of the Future Research Association, Brussels, Belgium.

Amadori, K., Mehdi, T., Ölvander, J., Krus, P. (2012), "Flexible and robust CAD models for design automation", Advanced Engineering Informatics, Vol. 26 No. 2, pp. 180-195. https://doi.org/10.1016/j.aei.2012.01.004

André, S., Elgh, F., Johansson, J. and Stolt, R. (2017), "The design platform - a coherent platform description of heterogeneous design assets for suppliers of highly customised systems", Journal of Engineering Design, Vol. 28 No. 10-12, pp. 599-626. https://doi.org/10.1080/09544828.2017.1376244

Andreasen, M.M. and Hein, L. (1987), Integrated Product Development, Institute for Product Development, Technical University of Denmark, Lyngby, Denmark.

Blessing, L. and Chakrabati, A. (2009), DRM - a Design Research Methodology, Springer, London, UK. https://doi.org/10.1007/978-1-84882-587-1

Boart, P. (2007), The enabling of product information in the conceptual phase, $\mathrm{PhD}$ thesis, Luleå University of Technology, Universitetstryckeriet, Luleå, Sweden.

Burstein, F. (2002), "System development in information systems research", In: Williamson, K. (Ed.), Research methods for students, academics and professionals - information management and systems, Centre for Information Studies, Wagga Wagga, pp. 147-158. https://doi.org/10.1016/B978-1-876938-42-0.50016-2

Cederfeldt, M. (2007), Planning design automation - a structured method and supporting tools, PhD thesis, Chalmers University of Technology, Chalmers Reproservice, Gothenburg, Sweden. 
Cederfeldt, M. and Sunnersjö, S. (2003), "Solid modelling with dimensional and topological variations", Proceedings ICED03, Stockholm, Sweden.

Claesson, A. (2006), A configurable component framework supporting platform-based product development, $\mathrm{PhD}$ thesis, Chalmers University of Technology, Chalmers Reproservice, Gothenburg, Sweden.

Curran, R., Verhagen, W.J.C., van Tooren, M.J.L. and van der Laan, T.H. (2010), "A multidisciplinary implementation methodology for knowledge- based engineering: KNOMAD", Expert Systems with Applications, Vol. 37 No. 11, pp. 7336-7350.

Duffy, A. and Andreasen, M.M. (1995), "Enhancing the evolution of design science", Proceedings ICED95, Praha, Czech Republic.

Elgh, F, (2012), "Decision support in the quotation process of engineered-to-order products", Advanced Engineering Informatics, Vol. 26 No. 1 pp. 66-79. https://doi.org/10.1016/j.aei.2011.07.001

Elgh, F. (2014), "Automated engineer-to-order systems - a task-oriented approach to enable traceability of design rationale", International Journal of Agile Systems and Management, Vol. 7 No. 3-4, pp. 324-347. https://doi.org/10.1504/IJASM.2014.065358

Elgh, F. and Cederfeldt, M. (2007), "Concurrent Cost Estimation as a Tool for Enhanced Producibility - System Development and Applicability for Producibility Studies”, Journal of Production Economics, Vol. 109 No. 12, pp. 12-26. https://doi.org/10.1016/j.ijpe.2006.11.007

Elgh, F. and Poorkiany, M. (2012). "Supporting Traceability of Design Rationale in an Automated Engineer-ToOrder Business Model”, Proceedings DESIGN 2012, Dubrovnik, Croatia.

Elgh, F., André, S., Johansson, J. and Stolt, R. (2016), "Design Platform: Setting the Scope and Introducing the Concept", Proceedings DESIGN 2016, Dubrovnik, Croatia.

Haug, A., Degn, A., Poulsen, B. and Hvam, L. (2007), "Creating a documentation system to support the development and maintenance of product configuration systems", Proceedings 2007 WSEAS International Conference on Computer Engineering and Applications, Queensland, Australia.

Hvam, L., Mortensen, N.H. and Riis, J. (2008), Product Customization, Springer Verlag, Berlin, Germany. https://doi.org/10.1007/978-3-540-71449-1

Isaksson, O. (2003), “A generative modeling approach to engineering design”, Proceedings ICED 03, Stockholm, Sweden.

La Rocca, G., Krakers, L.A. and van Tooren, M.J.L. (2002), "Development of an ICAD generative model for blended wing body aircraft design", Proceedings 9th AIAA/ISSMO symposium on multidisciplinary analysis and optimisation, Atlanta, GA, USA. https://doi.org/10.2514/6.2002-5447

Lisandrin, P. and van Tooren, M.J.L. (2002), "Generic volume element meshing for optimization applications", Proceedings 9th AIAA/ISSMO symposium on multidisciplinary analysis and optimisation, Atlanta, GA, USA. https://doi.org/10.2514/6.2002-5647

Rask, I. (1998), Rule-based product development - report 1, IVF Publication 98007 (in Swedish), Industrial Research and Development Corporation, Mölndal, Sweden.

Rask, I., Sunnersjö, S. and Amen, R. (2000), Knowledge Based IT-systems for Product Realization, VF Publication 00823 (in Swedish), Industrial Research and Development Corporation, Mölndal, Sweden.

Ryhänen, E. (2004), "A business strategy based on automated design and manufacture at Sandvik Coromant", JTH conference on "High variety products - Specials as standard”, Jönköping, Sweden.

Stokes, M. (2001), Managing engineering knowledge-MOKA, Professional Eng Publications ltd, London, Great Britain.

Ström, M., Raudberget, D., and Gustafsson, G. (2016), "Instant Set-Based Design, an Easy Path to Set-Based Design", Procedia CIRP, Vol. 50, pp. 234-239. https://doi.org/10.1016/j.procir.2016.04.194

Sunnersjö, S. (2012), "Planning design automation systems for product families - a coherent, top down approach", Proceedings Design 2012, Dubrovnik, Croatia.

van Tooren, M.J.L., La Rocca, G., Krakers, L.A. and Beukers, A. (2003), "Design and technology in aerospace: parametric modelling of complex structure systems", Proceedings 14th international conference on composite materials, San Diego, USA.

Verhagen, W.J.C., Bermell-Garcia, P., Van Dijk, R.E.C. and Curran, R. (2012), “A critical review of KnowledgeBased Engineering: An identification of research challenges", Advanced Engineering Informatics, Vol. 26 No. 1, pp. 5-15. https://doi.org/10.1016/j.aei.2011.06.004

Vinnova (2011), Challenge-driven innovation - Vinnova's new strategy for strengthening Swedish innovation capacity, Vinnova information vi 2011:07, Vinnova, Stockholm, Sweden.

Prof. Dr.-Ing. Fredrik Per Wilhelm Elgh

Jönköping University, School of Engineering, Product Development

P.O.Box 1026, 55111 Jönköping, Sweden

Email: fredrik.elgh@ju.se 